\title{
METODE PEMBELAJARAN “PICTURE AND PICTURE” DALAM MENULIS TEKS CERITA FIKSI NOVEL PADA BUKU TEKS BAHASA INDONESIA EKSPRESI DIRI DAN AKADEMIK SMA/ MA/ SMK/ MAK KELAS X11 SEMESTER 2 KURIKULUM 2013
}

\author{
Jamilatus Sa'adah \\ Universitas Islam Sultan Agung \\ risa.saadah626@gmail.com
}

Naskah diterima: 20 Januari 2017; direvisi: 8 Maret 2017; disetujui: 21 April 2017

\begin{abstract}
This study expects a teacher has learning methods to better support classroom learning, thus resulting in a productive and active learning. Indonesian textbooks and academic selfexpression SMA / MA / SMK / MAK class XII 2nd semester curriculum in 2013, the Ministry of education and culture through learning to write fiction in the novel. This study uses a method that is Pictur Picture and Picture and Picture Learning model is a learning method that uses images and paired or sorted into a logical sequence. Learning is characterized Active, Innovative, Creative, and Fun. Learning Model relies images as a medium of learning. These images become a major factor in the learning process. In pulling teaching of writing fiction in the novel, the author tried to examine the learning method and Pictur Picture.
\end{abstract}

Keywords: learning, literary fiction, and Picture and Pictur.

\begin{abstract}
ABSTRAK
Penelitian ini mengharapakan seorang pengajar memiliki metode pembelajaran untuk mendukung kelancaran pembelajaran dikelas, sehingga menghasilakan pembelajaran yang produktif dan aktif. dalam buku teks bahasa indonesia ekspresi diri dan akademik SMA/ MA/ SMK/ MAK kelas XII semester 2 kurikulum 2013, Kementrian pendidikan dan kebudayaan melalui pembelajaran menulis cerita fiksi pada novel. Penelitian ini menggunakan metode Picture and Pictur yaitu Model pembelajaran Picture and Picture adalah suatu metode belajar yang menggunakan gambar dan dipasangkan atau diurutkan menjadi urutan logis. Pembelajaran ini memiliki ciri Aktif, Inovatif, Kreatif, dan Menyenangkan. Model Pembelajaran ini mengandalkan gambar sebagai media dalam proses pembelajaran. Gambar-gambar ini menjadi faktor utama dalam proses pembelajaran. Dalam menariknya pembelajaran menulis cerita fiksi dalam novel maka penulis mencoba meneliti pembelajaran tersebut menggunakan metode Picture and Pictur.
\end{abstract}

Kata Kunci : pembelajaran, cerita fiksi sastra, dan Picture and Pictur.

PENDAHULUAN

Pembelajaran bahasa dan sastra Indonesia diberbagai penjuru pendidikan selama ini masih dianggapa kurang penting sehingga dalam pembelajaran siswa kurang menumbuhkan ketrampilan terhadap bahasa dan satra Indonesia. Dalam hal metode pembelajaran masih kuarang 
adanya keratifitas seorang guru dalam mengajarakan pembelajaran sastra tidak, hanya metode pembelajran ceramah dan diskusi. Dari banyaknya metode pembelajaran maka pembelajaran bahasa dan sastra maka akan lebih aktif dan produktif untuk mengajar peserta didik di kelas.

Pada pembelajaran Sastra Indonesia pada buku teks bahasa indonesia ekspresi diri dan akademik SMA/ MA/ SMK/ MAK kelas XII semester 2 kurikulum 2013, terdapat Kompetensi Inti ( KI ) Kegiata 2. Kerja Bersama Membangun Teks Cerita Fiksi dalam Novel dengan Kompetensi Dasar (KD) Tugas 3. Memproduksi Teks Cerita Fiksi dalam Novel secara Bersama.

Menurut Rosta Maji dan Priant Oro, novel merupakan karya satra yang mempunyai dua unsur yaitu unsur Intrinsik dan unsur ekstrinsik yang kedua saling berhubungan karena sangat mempengaruhi dalam kehadiran sebuah karya sastra. Genre fiksi merupakan jenis teks yang dibuat berdasarkan dunia imajinasi berdsarkan pengalaman pandangan tafsiran, wawasan dan penilaianya terhadap peristiwa secara nyata maupun hanya khayalan ditungkan dalam sebuah tulisan. Unsur-unsur fiksi (1) Intrinsik, (2) Ekstrinsik, (3) Fakta, (4) Tema, (5) Saran, (6) cerita, (8) Cerita, dan (7) wacana.

Pembelajaran menulis cerita fiksi dalam novel merupakan kegiatan mewujudkan pikiran dan perasaan dalam imajinasi terhadap sebuah peristiwa yang nyata maupun khayalan yang dapat membantu peserta didik untuk mengekspresikan pengalamannya, dengan pembelajaran seorang pengajar sangat diperlukan pembelajaran yang tepat. Peneliti mencoba meneliti mengunakan metode picture and picture untuk tujuan pembelajaran bisa tercapai.

\section{METODE PENELITIAN}

Metode pembelajaran adalah cara penggolongan peserta didik. Pada dasarnya metode atau pendekatan pembelajaran yang digunakan pada Buku Teks Bahasa Indonesia Ekspresi Diri Dan Akademik
Sma/ Ma/ Smk/ Mak Kelas X11 Semester 2 Kurikulum 2013, karangan Kementerian pendidikan dan kebudayaan. bergantung dengan isi materinya. Dalam hal ini metode ceramah, diskusi kelompok, individu, presentasi, demonstrasi, bermain peran, belum tentu sesuai dengan semua materi yang disajikan. Metode atau pendekatan yang digunakan guru dalam pengajaran harus bervariasi untuk menghindari kebosanan siswa. Hal ini dapat dilakukan guru dengan cara memvariasikan metode Picture and picture dalam pembelajaran menulis cerita fiksi pada Novel.

Objek penelitian yang dianalisis adalah pada Buku Teks Bahasa Indonesia Ekspresi Diri Dan Akademik Sma/ $\mathrm{Ma} /$ Smk/ Mak Kelas X11 Semester 2 Kurikulum 2013 Pembelajaran menulis Cerita Fiksi pada Nove. Menggunakan menggunakan metode picture and picture.

Sumber data yang digunakan dalam penelitian ini adalah sumber data kepustakaan yaitu berupa buku, transkip, majalah dan lain-lain. Hal ini sejalan dengan perincian sebagai berikut.

Sumber data primer dalam penelitian ini adalah Buku Teks Bahasa Indonesia Ekspresi Diri Dan Akademik Sma/ Ma/ Smk/ Mak Kelas X11 Semester 2 Kurikulum 2013 pada pembelajaran menulis cerita fiksi novel.

Sumber data sekunder dalam penelitian ini adalah buku dan Jurnal yang mempunyai relevansi untuk memperkuat argumentasi dan melengkapi hasil penelitian ini. Seperti Jurnal "Efektivitas model pembelajaran Latihan penelitian terhadapa kemampuan menganalisis nilai-nilai moral cerpen sampan zulaikahah karya Hasan AlBnanna siswa kelas $X$ SMA negri 1Tanjung Balai tahun pembelajaran 2010/2011" karya Devi Sainar purha.

Wujud data dalam penelitian ini berupa buku teks cerita fiksi pada Novel yang di sediakan dalam Buku Teks Bahasa Indonesia Ekspresi Diri Dan Akademik Sma/ Ma/ Smk/ Mak Kelas X11 Semester 2 Kurikulum 2013. 


\section{HASIL DAN PEMBAHASAN}

\section{Metode Pembelajaran}

Metode pembelajaran merupakan teknik guru yang digunakan menyajikan bahan pembelajaran kepada peserta didik agar pembelajaran tersebut dapat dipahami oleh peserta didik dengan baik. Menulis teks cerita fiksi pada Novel sangat dibutuhkan metode yang tepat. Metode Picture and Pictur sangat cocok untuk pembelajaran menulis certia fiksi pada novel. Dengan menggunakan metode tersebut peserta didik akan menungkan wawasan, pengalamannya dengan nyata maupun khayalan,

Metode Pembelajaran Picture and Pictur ini mengandalkan gambar sebagai media dalam proses pembelajaran. Gambar-gambar ini menjadi factor utama dalam proses pembelajaran. Sehingga sebelum proses pembelajaran guru sudah menyiapkan gambar yang akan ditampilkan baik dalam bentuk kartu atau dalam bentuk carta dalam ukuran besar. Atau jika di sekolah sudah menggunakan ICT dalam menggunakan Power Point atau software yang lain.

Menurut Johnson \& Johnson, prinsip dasar dalam metode pembelajaran kooperatif picture and picture adalah sebagai berikut:

1. Setiap anggota kelompok (siswa) bertanggung jawab atas segala sesuatu yang dikerjakan dalam kelompoknya.

2. Setiap anggota kelompok (siswa) harus mengetahui bahwa semua anggota kelompok mempunyai tujuan yang sama.

3. Setiap anggota kelompok (siswa) harus membagi tugas dan tanggung jawab yang sama di antara anggota kelompoknya.

4. Setiap anggota kelompok (siswa) akan dikenai evaluasi.

5. Setiap anggota kelompok (siswa) berbagi kepemimpinan dan membutuhkan keterampilan untuk belajar bersama selama proses belajarnya.

6. Setiap anggota kelompok (siswa) akan diminta mempertanggungjawabkan secara individual materi yang ditangani dalam kelompok kooperatif.

Sesuai dengan namanya, tipe ini menggunakan media gambar dalam proses pembelajaran yaitu dengan cara memasang/mengurutkan gambar-gambar menjadi urutan yang logis.

Kelebihan dan kekurangan model pembelajaran Picture and Picture:

\section{Kelebihan:}

a. Guru lebih mengetahui kemampuan masing-masing siswa.

b. Melatih berpikir logis dan sistematis.

c. Membantu siswa belajar berpikir berdasarkan sudut pandang suatu subjek bahasan dengan memberikan kebebasan siswa dalam praktik berpikir,

d. Mengembangkan motivasi untuk belajar yang lebih baik.

e. Siswa dilibatkan daiam perencanaan dan pengelolaan kelas.

\section{Kekurangan:}

Memakan banyak waktu. Banyak siswa yang pasif. Guru khawatir bahwa akan terjadi kekacauan dikelas. Banyak siswa tidak senang apabila disuruh bekerja sama dengan yang lain. Dibutuhkan dukungan fasilitas, alat dan biaya yang cukup memadai

\section{Media Pembelajaran}

Media pembelajaran menurut Hamalik (1994:12) adalah alat, metode, dan teknik yang digunakan dalam rangka lebih mengefektifkan komunikasi dan interaksi antara guru dan siswa dalam proses pendidikandan pengajaran di sekolah.

Model pembelajaran Picture and Picture adalah suatu metode belajar yang menggunakan gambar dan dipasangkan atau diurutkan menjadi urutan logis. Pembelajaran ini memiliki ciri Aktif, Inovatif, Kreatif, dan Menyenangkan. Model Pembelajaran ini mengandalkan gambar sebagai media dalam proses pembelajaran. Gambar-gambar ini menjadi faktor utama dalam proses pembelajaran. 


\section{Memilih Gambar yang Baik Dalam Pengajaran}

Dalam pemilihan gambar yang baik untuk kegiatan pengajaran terdapat beberapa kriteria yang perlu diperhatikan antara lain:

a. Keaslian gambar. Gambar menunjukkan situasi yang sebenarnya, seperti melihat keadaan atau benda yang sesungguhnya. Kekeliruan dalam hal ini akan memberikan pengaruh yang tak diharapkan gambar yang palsu dikatakan asli.

b. Kesederhanaan. Gambar itu sederhana dalam warna, menimbulkan kesan tertentu, mempunyai nilai estetis secara murni dan mengandung nilai praktis. Jangan sampai peserta didik menjadi bingung dan tidak tertarik pada gambar.

c. Bentuk item. Hendaknya sipengamat dapat memperoleh tanggapan yang tetap tentang obyek-obyek dalam gambar.

d. Perbuatan. Gambar hendaknya hal sedang melakukan perbuatan. Peserta didik akan lebih tertarik dan akan lebih memahami gambar-gambar yang sedang bergerak.

e. Fotografi. Peserta didik dapat lebih tertarik kepada gambar yang nilai fotografinya rendah, yang dikerjakan secara tidak profesional seperti terlalu terang atau gelap. Gambar yang bagus belum tentu menarik dan efektif bagi pengajaran.

f. Artistik. Segi artistik pada umumnya dapat mempengaruhi nilai gambar. Penggunaan gambar tentu saja disesuaikan dengan tujuan yang hendak dicapai.

\section{SIMPULAN}

Berdasarkan ulasan pada hasil penelitian dan pembahasan dalam penelitian Buku Teks Bahasa Indonesia Ekspresi Diri Dan Akademik Sma/ Ma/ Smk/ Mak Kelas X11 Semester 2 Kurikulum 2013 pada pembelajaran menulis cerita fiksi novel dengan menggunakan metode picture and picture menjadi urutan logis. Pembelajaran ini memiliki ciri Aktif, Inovatif, Kreatif, dan Menyenangkan. Model Pembelajaran ini mengandalkan gambar sebagai media dalam proses pembelajaran. Gambargambar ini menjadi factor utama dalam proses pembelajaran. Metode pembelajaran picture and picture juga memiliki kekurangan, dengan kekurangan metode pembelajaran picture and picture dapat dilengkapai dengan kelebihannya.

\section{DAFTAR PUSTAKA}

Devi Sainar Purha. 2010. Efektivitas Model Pembelajaran Latihan Penelitian Terhadap Kemampuan Menganalisis Nilai-nilai Moral Cerpen Sampan Zulaikahah karya Hasan Al-Bnanna Siswa Kelas X SMA $N$ ITanjung Balai Tahun Pembelajaran 2010/2011. Jurnal. Medan: Universitas Negri Medan.

Hari Santoso. 2011. Membangun Minat Baca Anak Usia Dini Melalui Penyediaan Buku Bergambar. Jurnal. Malang: Universitas Negri Malang.

Kementerian Pendidikan dan Kebudayaan. 2015. Bahasa Indonesia Ekspresi Diri Dan Akademik Sma/ Mal Smk/ Mak Kelas X11 Semester 2 Kurikulum 2013. Jakarta. Pusat Kurikulum dan Perbukuan, Balitbang, Kemdikbud.

Panca Dewi Purwati, Fatur Rahmana, Agus Nur Yatin. 2012. Mengembangan Media Bangunan Multifikasi untuk Peningkatan Kompetensi Menulis Cerita Pendek Siswa SMP. Jurnal. Semarang: Universitas Negeri Semarang

Pendes. 2013. Penggunaan media gambar dalam proses. Diunduh pada tanggal 08 Januari 2017. http://pendas2013.blogspot.co.id/20 13/01/penggunaan-media-gambardalam-proses.html 